\title{
Incidence and distribution of neomembranes of dura mater ${ }^{1}$
}

\author{
REINHARD L. FRIEDE \\ From the Institute of Pathology, Case Western Reserve University, Cleveland, Ohio, U.S.A.
}

SUMMARY Membranous or membranous-haemorrhagic lesions of the dura mater were found in 46 out of 1,044 consecutive necropsies after excluding those cases where their presence could be interpreted in terms of blood dyscrasia, local neoplastic processes, previous surgery, or marked craniocerebral trauma. The extent of old and recent manifestations of haemorrhage in the membranes increased in a statistically significant relation with their size and thickness. Lesions of different types, or degrees, respectively, were often combined in the same case; a remarkably high incidence of membranous lesions in the falx cerebri was noted. The observations indicate the presence of a progressive, repetitive process in neomembrane formation.

The literature on chronic subdural haematoma is dominated by more than a century of controversy concerning its pathogenesis, dating back to the very first descriptions of the disease. Heschl (1855) suggested that an inflammatory disease of the dura mater produces hypervascularization and haemorrhage. This concept was accepted by Virchow (1857), Cruveilhier (1865), and Kremiansky (1868), who considered the haemorrhage a complication of a primary degenerative or inflammatory disease. Huguenin (1876) and Mittenweig (1889), on the other hand, demonstrated stumps of ruptured veins in the subdural haematomas; Wiggelsworth (1892) proposed that membrane formation was secondary to haemorrhage; Trotter (1914) concluded that subdural haemorrhages are 'quite invariably' due to trauma tearing large veins. These opposing points of view were elaborated further by Jores (1898), Jores and Laurent (1901), Henschen (1930), v. Albertini (1941, 1942), Link (1945), Link and Schleussing, (1955), Wepler (1951, 1954a, b, 1959), Soos and Detrehazy (1955), and Gellersted (1956), who attempted to strengthen the hypothesis of pachymeningeosis (Henchen, 1930) by studies of the structure of neomembranes, while Hanke (1939), Munro and Merritt (1936), Munro (1942), Leary (1934), Christensen (1941, 1956), and Krauland (1961) attributed subdural haemorrhagic lesions invariably to trauma. Several authors (Jores and

1This investigation was supported by Public Health Grant NB 06239 from the National Institute of Neurological Diseases and Stroke.
Laurent, 1901; Putnam and Cushing, 1925; v. Albertini, 1941, 1942; Link, 1954; Peters, 1951a,b; Wolf, 1962) accepted both pathogenetic concepts as equally valid for different types of subdural haematomas. Experimental investigations have contributed little toward clarifying these controversies. Single subdural injections of blood failed to produce chronic subdural haematomas in experimental animals (Putnam and Putnam, 1927; Gardner, 1932; Pampari, 1938), the resultant haematoma being subject to rapid organization and regression without developing chronicity (Goodell and Mealy, 1963). Lesions resembling chronic subdural haematomas were produced with repeated injections of blood causing chronic inflammation (Zehnder, 1938; Hoff and Tschabitscher, 1953).

The present study was stimulated by the observation that careful examination of the dura mater in routine necropsy material revealed a surprisingly high incidence of minor membranous, or membranous-haemorrhagic lesions, clinically asymptomatic, for which a cause was not apparent in either the general necropsy findings, the history, or in local disease processes involving the dura mater. The present report excludes cases in which the presence of neomembranes or haemorrhages was explicable in terms of blood dyscrasia, carcinomatous or leukaemic infiltrates of dura, surgical intervention, and nearly all cases with positive history of craniocerebral trauma. After exclusion of these nonproblematic cases, there remained 46 cases out of a series of 1,044 consecutive necropsies, collected over 
a three-year period, in which the lesions were minor and asymptomatic and for which there was absent, tenuous, or conflicting relationship to craniocerebral trauma and none to other local or general disease processes. The incidence of membranous lesion in the falx cerebri was remarkably high, although few were patently haemorrhagic.

\section{METHODS}

All 46 brains with attached falx and parietal dura mater were fixed in neutral formalin by suspension from the basilar artery. The dura mater covering the basal surface of the skull was also collected. The dura mater and falx were flattened under a piece of plate glass, making radial incisions where necessary. Planimetric measurements were made through the glass plate of the size of the membranes and of all the haemorrhages in the membranes, using an Ott disk planimeter. The percentage of the membrane area occupied by haemorrhages was calculated. Sections were cut from the thickest portions of the lesions, as well as from the edges, and stained, in each case, with haematoxylin eosin, Masson, Prussian blue, van Gieson, and periodic acid-Schiff. Serial sections were cut parallel to the surface of the dura mater or through the neomembranes in selected cases. The thickness of the membranes, exclusive of any haematoma, was measured with an ocular micrometer; no effort was made to correct these measurements for shrinkage during paraffin embedding. Haemophages were counted in sections stained for iron; counts were made to the nearest 10 or the nearest 100 respectively per field, using a $10 x$ objective and a 12.5x wide-field eyepiece. Haemophage density varied greatly from region to region, so that only a broad range could be indicated in the protocols-for example, 0 to 10 or 20 to 100 . Only counts made in sections stained for iron were considered reliable, because grains of formalin pigment, representing a fixation-dependant artefact, were often clustered in macrophages.

\section{RESULTS}

Membranous and membranous-haemorrhagic lesions were incidental findings in the cranial dura mater of 46 cases out of 1,044 consecutive necropsies. Their incidence was nearly equally divided between $=$ the sexes $(55 \%$ male); $67 \%$ of the cases weres Caucasian, corresponding roughly to the composition of our necropsy material. The average age was 68.50 years, the youngest 33 and the oldest 97 years; this? age distribution corresponded with the ranges? reported for subdural haematomas by Ciarla (1933) and Wolf (1921); whereas statistics based mainly on acute traumatic cases showed a younger average age $\overrightarrow{\vec{m}}$ (Hanke, 1939; Krauland, 1961). Four types of lesions were readily distinguished (Link, 1945; Link듬 and Schleussing, 1955): (I) thin, densely vascularized $\overline{\bar{\omega}}$ neomembranes without haemorrhage or with only $a \overrightarrow{\widetilde{\Phi}}$ few petechiae, (II) neomembranes with multicentric, sometimes partly confluent, haemorrhages, (III) incidental, subdural haematomas, encapsulated by $\vec{\circ}$ neomembranes, (IV) dense fibrotic lesions, with, or without, central encapsulated haematoma or hygroma. $\vec{~}$ None of the 46 cases showed evidence of ruptured veins upon inspection of the dura mater while it was? still attached to the cerebral hemispheres. It was com-iw mon to observe multiple lesions in a given case; of $f_{-}^{\oplus}$ those in the parietal dura mater, 22 were unilaterogl and 20 bilateral, and 27 cases had lesions in the fa:. Counting the individual lesions, there were 88 으응 sions in the 46 cases, 37 of type I, 15 of type II, 16 of type III, and 20 of type IV. The breakdown into dividual lesions was prompted by the observationo that multiple lesions in a given case were often 5 fos different types, as shown in Tables 1 and 2 . description of the characteristic features of each type of lesion follows.

NEOMEMBRANES WITHOUT HAEMORRHAGES (TYPE I) These lesions can easily be overlooked, showing noo haemorrhages, or only a few petechiae occupyingo less than $10 \%$ of the neomembrane; yellow dis- $\Omega$ colouration was absent. Such neomembranes pre- $\overrightarrow{0}$ sented themselves as dull, vascularized patches on 3 the glossy surface of the dura mater and were?

$$
\text { 衰 }
$$

TABLE 1

LESIONS IN CONTRALATERAL DURA MATER (EXCLUDING LESIONS IN FALX)*

\begin{tabular}{|c|c|c|c|c|c|}
\hline Main lesion & $\begin{array}{c}\text { No contralateral } \\
\text { lesion }\end{array}$ & $\begin{array}{c}\text { Contralateral } \\
\text { neomembrane } \\
\quad(\text { type I) }\end{array}$ & $\begin{array}{c}\text { Contralateral } \\
\text { haemorrhagic } \\
\text { neomembrane } \\
\quad(\text { type II) }\end{array}$ & $\begin{array}{c}\text { Contralateral } \\
\text { haematoma } \\
\text { (type } I I I)\end{array}$ & $\begin{array}{c}\text { Contralateral } \\
\text { fibrosis } \\
\text { (type IV) }\end{array}$ \\
\hline
\end{tabular}

Neomembrane (type I)

Haemorrhagic neomembrane (type II)

Haematoma (type III)

Fibrosis (type IV)

4
1
6
22 unilateral
lesions

*Indexed according to the main lesion, regardless of whether left or right. 
TABLE 2

LESIONS IN THE FALX ASSOCIATED WITH LESIONS IN THE PARIETAL DURA MATER

\begin{tabular}{|c|c|c|c|c|c|}
\hline $\begin{array}{c}\text { Main lesion in } \\
\text { parietal dura mater }\end{array}$ & $\begin{array}{l}\text { No pathology } \\
\text { in falx }\end{array}$ & $\begin{array}{c}\text { Neomembrane } \\
\text { in falx } \\
\text { (type I) }\end{array}$ & $\begin{array}{c}\text { Haemorrhagic } \\
\text { neomembrane } \\
\text { (type II) } \\
\text { in falx }\end{array}$ & $\begin{array}{c}\text { Haematoma } \\
\text { in falx } \\
(\text { type } I I I)\end{array}$ & $\begin{array}{c}\text { Fibrosis } \\
\text { in falx } \\
\text { (type IV) }\end{array}$ \\
\hline $\begin{array}{l}\text { No pathology } \\
\text { Neomembrane (type I) } \\
\text { Haemorrhagic neomembrane (type II) } \\
\text { Haematoma (type III) } \\
\text { Fibrosis (type IV) }\end{array}$ & $\begin{array}{c}\text { Not collected } \\
1 \\
3 \\
5 \\
11 \\
20 \text { parietal lesions } \\
\text { without falx lesions }\end{array}$ & $\begin{array}{l}4 \\
6 \\
3 \\
5 \\
1\end{array}$ & $\begin{array}{c}- \\
-1 \\
2 \\
2 \\
4 \text { lesions } i \\
\text { lesions associ }\end{array}$ & $\begin{array}{l}- \\
\overline{-} \\
\text { only } \\
\text { with parietal } 1\end{array}$ & $\begin{array}{l}\overline{1} \\
\frac{1}{1}\end{array}$ \\
\hline
\end{tabular}

easily detached by scraping. Their mean area was 12 sq. $\mathrm{cm} \pm 2 \cdot 3$ and their mean thickness $0.17 \mathrm{~mm} \pm$ 0.02 ( \pm signifies standard deviations); there was no statistically significant difference in the size or thickness of type I neomembranes on the falx and the parietal dura mater. A grouping by observed frequencies showed that only $11 \%$ of these neomembranes were larger than $20 \mathrm{sq}$. $\mathrm{cm}$. The neomembranes showed a characteristic, prominent vascularization in spider pattern or in dense patches (Figs. 1, 2). The vessels differed in arrangement from congested intradural vessels which ran parallel to the trabeculae of connective tissue (Fig. 3) and could not be detached by scraping.

Microscopic examination revealed a thin layer of loose proliferating fibroblasts on the inner surface of the dura mater; collagen fibres were sparse or absent. No haemophages were found in $29 \%$ of the lesions and less than 10 per field in $45 \%$. Sinusoid, thinwalled blood vessels abounded throughout the membrane, some protruding partially above its surface (Figs. 4, 5). Sinusoids were found even in the thinnest membranes, where they appeared freely suspended from the inner surface of the dura mater supported by only a few scattered fibroblasts (Fig. 4). This suggested that vascular proliferation beyond the inner surface of the dura mater was one of the primary features of neomembrane formation (v. Albertini, 1941, 1942). If petechiae were present, they were mostly of recent date in showing no cytolysis and no reactive changes or organization respectively at their edges. A delicate fibrinous exudate on or in the neomembrane was seen in three membranes.

NEOMEMBRANES WITH MULTIPLE OR CONFLUENT HAEMORRHAGES (TYPE II) These lesions were distinguished from the type I lesions in the extent of haemorrhages in the membrane. The lesions in this category varied from a few small petechiae occupying barely more than $10 \%$ of the membrane to 'tigered' lesions with innumerable, small effusions (Figs. 6, 7).
In still other cases, larger, multifocal, but partly confluent haemorrhages formed a gradial transition to subdural haematomas of type III. Lesions of this type were statistically significantly larger $(59 \mathrm{sq} . \mathrm{cm}$ $\pm 13)$ and thicker $(0.32 \mathrm{~mm} \pm 0.07)$ than lesions of type I $(P<0.01)$. Rusty discolouration of the membrane was usually absent. In routine necropsies these lesions tend to be diagnosed as subdural haematomas only when the haemorrhages are large and become confluent. The lesser lesions are usually considered 'incidental' petechiae in dura mater, ignoring the much larger neomembranes in which they are located.

The microscopic appearance of such membranes was similar to that of type I, except that they were thicker and showed more haemophages in iron stains; $67 \%$ showed 10 to 100 haemophages per field. The haemorrhages seen grossly were extravasations of non-lysed erythrocytes into the loose connective tissue of the neomembrane, often in proximity to a congested sinusoid vessel, and most appeared of recent date. Clusters of haemophages in other portions of the membrane indicated older organized haemorrhages. Inflammatory infiltrates were rare and mostly absent.

CHRONIC SUBDURAL HAEMATOMA (TYPE III) Six cases with typical chronic subdural haematomas were included into this series because the haematomas were thin, clinically not detected, and were found in association with other types of membranous lesions. Two of the cases showed bilateral chronic subdural haematoma, three contralateral haemorrhagic neomembranes of type II, and three contralateral nonhaemorrhagic neomembranes of type I (Table 1). Five of the six cases also showed associated lesions in the falx (Table 2). These haematomas were significantly larger $(P<0.001)$ than the neomembranes of type II (87 sq. $\mathrm{cm} \pm 10)$ and their membranes were significantly thicker $(0.64 \mathrm{~mm} \pm 0.14)$. The membranes contained more collagen tissue, tended 


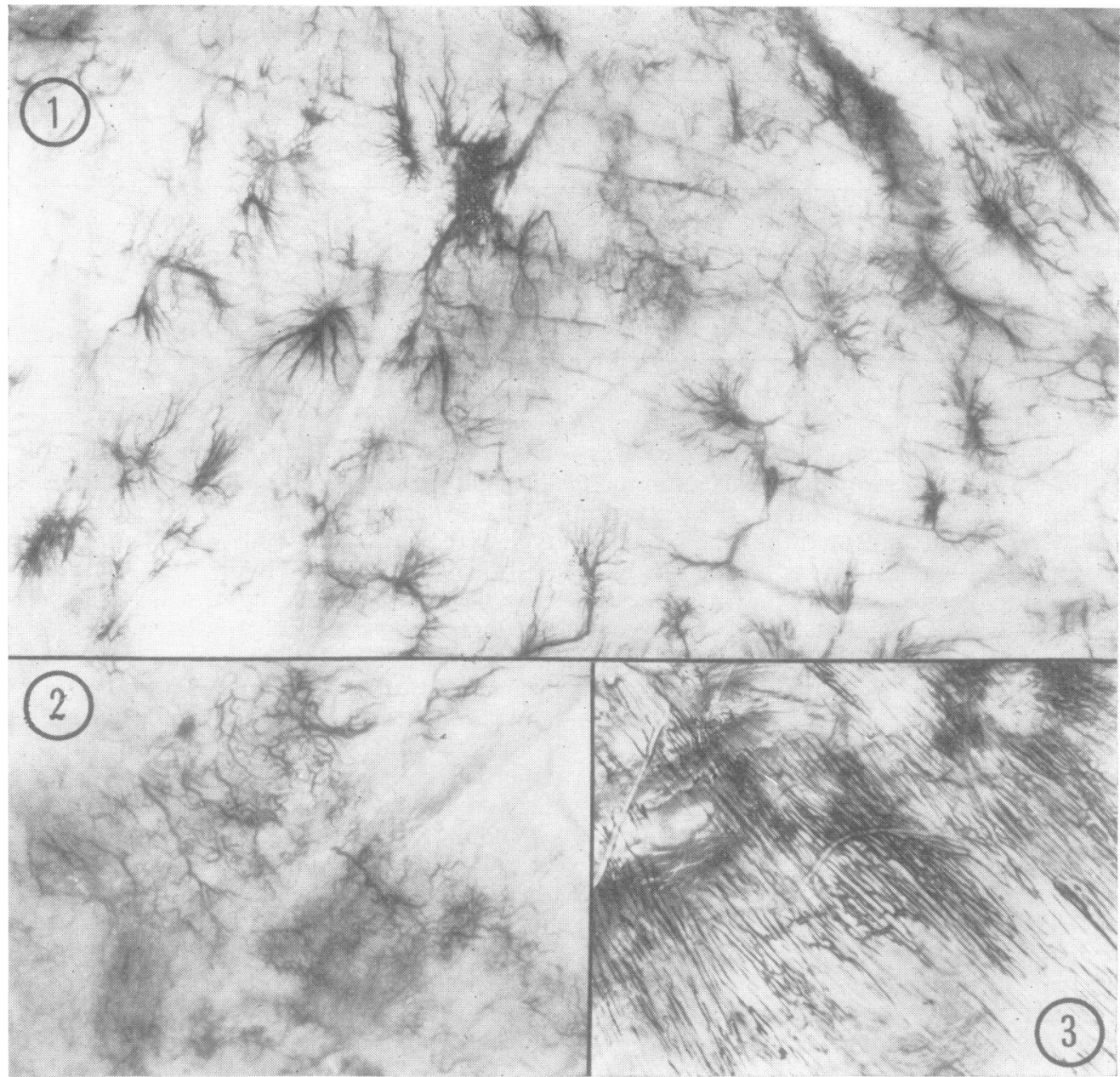

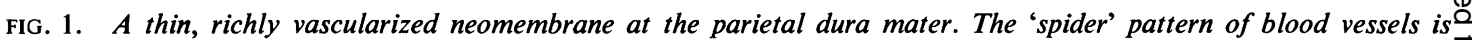
prominent. The neomembrane itself is extremely thin and may escape attention, except for the dullness of its surface. $\overrightarrow{\vec{O}}$ Vessels and membrane scratched off easily. No portion of this membrane showed gross pigmentation, haemophages, or 3 fresh haemorrhage. $\times 2$.

FIG. 2. Small area of neomembrane in the falx; no indication of haemorrhage. $\times 2$.

FIG. 3. Falx in a case with marked chronic, passive congestion. Note the difference in vascular architecture as compared with vessels in the neomembrane in Fig. 2. The vessels in Fig. 2 scratched off with the membrane, those in Fig. 3 did not. $\times 2$.

to be pigmented grossly, and haemophage densities were high but varied greatly-80\% showing 10 to 100 haemophages per field. Chronic inflammatory infiltrates were common. Inner and outer neomembranes fused at the edge of the haematoma extending for some distance beyond the latter; prominent vascularization was present in this fused portion, similar to the vascularization seen in the $\frac{\text { ? }}{5}$ lesions of type I or II.

FIBROTIC LESIONS (TYPE IV) These were evidently old, inactive lesions characterized by a layer of firm collagen tissue resembling normal dura mater in density. They presented as roughened areas of solid $\omega$ 

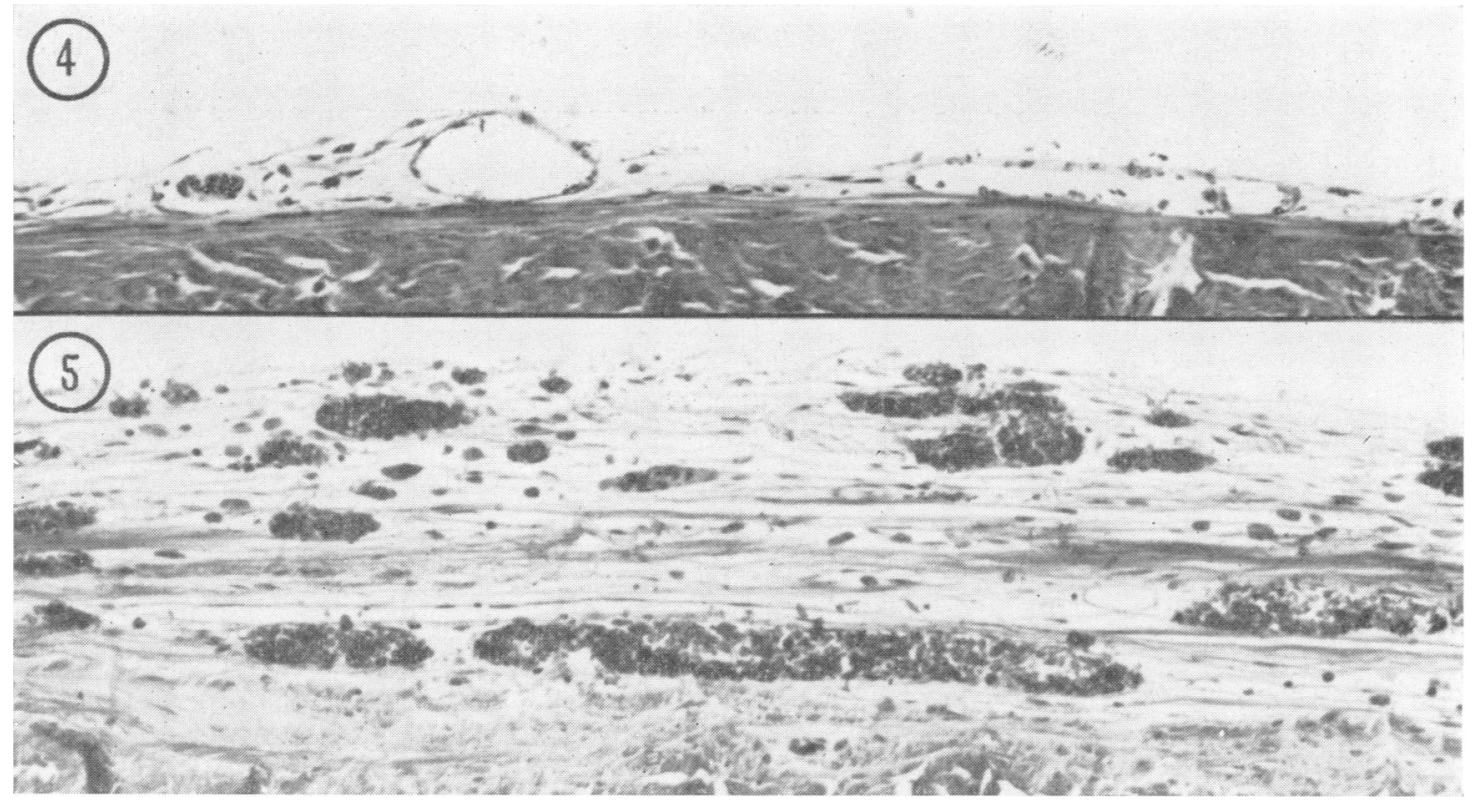

FIG. 4. Extremely thin neomembrane consisting of a few, thin-walled sinusoid vessels that appear to be suspended from the inner surface of the dura mater with very few interspaced fibroblasts. Gross features of this specimen were similar to those shown in Fig. 1. $H$ and $E, \times 140$.

FIG. 5. Abundant thin-walled, sinusoid blood vessels in a thin neomembrane without haemorrhages. $\times 140$.

fibrotic thickening of the dura mater or they formed a firm, fibrous capsule around a hygroma or liquefied haematoma. Yellowish-brownish pigmentation was present in slightly less than half of the lesions. These lesions were easily overlooked unless pigmentation or a central cavity drew attention to their presence. The increased vascularization found in neomembranes of type I and II was absent in most instances. These lesions tended to be large ( 60 sq. $\mathrm{cm} \pm 14)$ and thick $(1.01 \mathrm{~mm} \pm 0 \cdot 27)$, but both parameters showed no significant difference with lesions of type III. Microscopic examination revealed thick layers of mature collagen tissue, with sparse nuclei of mature fibrocytes among the collagen bundles. Fibrotic areas lacked inflammatory infiltrates. Haemophage density varied greatly from case to case, sometimes reaching extreme values of up to and beyond 500 per field. Half of the lesions contained more than 50 haemophages per field. The density of blood vessels resembled that of normal dura mater; vessels were thin walled but, contrary to the neomembranes of type I or II, they were encompassed entirely by dense collagen tissue. The regular layered architecture of the dura mater was distinguishable from the random fibrosis in the overlying scar tissue. Fibrotic membranes encompassing a central liquefied haematoma or hygroma showed more inflammatory infiltrates and macrophages than solid membranes. Degenerative changes of the connective tissue near the central cavity were also observed.

A review of necropsy protocols and hospital charts for each of these cases showed a high incidence of diabetes and cardiovascular disease, but the frequencies corresponded with those observed in the general necropsy material without indicating a relation to the presence of dural neomembranes. No clinical observations relating to the presence of thin neomembranes were found. Special attention was paid to any possible history of craniocerebral trauma. There were four alcoholics and two epileptics in this series; these were considered to have a presumptive history of craniocerebral trauma, although specific data were absent. Five of them showed unilateral, fibrotic lesions of type IV in the parietal dura mater, the sixth had a neomembrane of type $I$ at the falx. Four patients had a definite history of trauma, but only two showed a correspondence between clinical history and necropsy findings; these two patients had reported slight trauma and had thin haematomas of type III, however, associated with other types of lesions. The other two cases revealed a definite discrepancy between the clinical history and the 


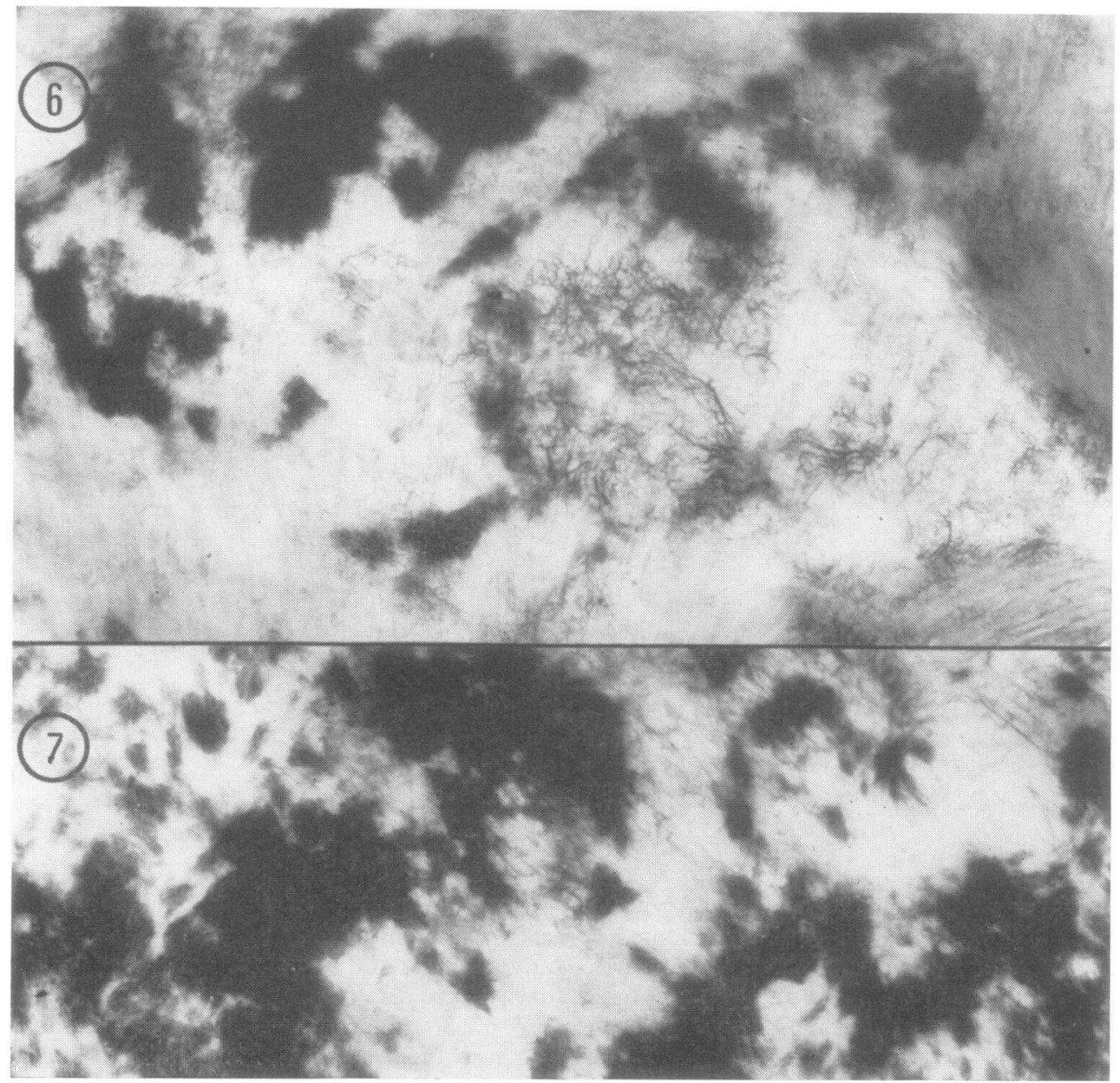

FIG. 6. Neomembrane with multiple, recent haemorrhages, some of which are confluent. $\times 2$.

FIG. 7. Neomembrane with abundant recent haemorrhages, some small, others confluent. The rich vascularization of the neomembrane is obscured by haemorrhages. $\times 2$.

pathological findings-for example, a case with a fall from a ladder seven years before death showed a very thin neomembrane with petechial haemorrhages, obviously of recent date. The lack of correlation between the presence of neomembranes and craniocerebral trauma in our series is stressed in one patient who had been bedridden with multiple sclerosis for many years, yet showed extremely large, bilateral neomembranes of type II with abundant recent and old haemorrhages.

\section{DISCUSSION}

Electron microscopic studies of the dura-arachnoid interface after fixation in situ show that the inner dural surface is covered by a layer of lamellated processes which are in contact with the arachnoid cells, separated by a gap only approximately $200 \AA$ wide (Andres, 1966, 1967a, b; Beggs, 1967). This lamellated layer of processes-called 'subdural neurothel'-is rich in pinocytotic vesicles. Anoxia results in rapid enlargement of the intercellular clefts (Andres, 1967) and in separation of dura and arachnoid maters. The smooth glossy inner surface of normal dura mater observed under routine necropsy conditions may thus represent a post mortem artefact, albeit a constant one. Under ordinary necropsy conditions the normal dura mater 
does not show a 'stratum meningeale' (Krempien, 1967,1968 ), or an innermost layer of loose vascularized tissue (Link, 1945, Wepler, 1954a, b; Link and Schleussing, 1955; Wepler, 1959). The presence of such tissue represents neomembrane formation and should be considered abnormal.

The causes for the formation of a neomembrane in normal dura mater are not clear. It is possible that all the neomembranes observed in the present series were secondary to organization of traumatic subdural haemorrhages. However, if this were the case, subdural haemorrhage, without history of trauma, or upon very minimal insults, would be more frequent than generally assumed; moreover, such incidents would tend to recur, as suggested by the various combinations of types of lesions found in many of our cases (Tables 1, 2).

The present observations were considered consistent with the assumption that neomembrane formation may begin as a primary, probably agerelated degenerative process at the inner surface of the dura mater. Proliferation of large sinusoid capillaries beyond the inner surface of the dura mater appears to be one of the earliest features of the process. These sinusoids are probably extremely vulnerable to minimal trauma, thus initiating a vicious circle of proliferation and haemorrhage. This interpretation is consistent with the lack of haemophages or any other evidence of haemorrhage in more than one fourth of the very thin membranes of type $\mathrm{I}$; it is also consistent with the prevalence of non-haemorrhagic neomembranes at the falx, where they are probably less exposed to mechanical insults. The interpretation also agrees with an active proliferation of fibroblasts in the thin neomembranes of types I and II and with the mature collagen and fibrocytes in the lesions of type IV which were considered inactive scars.

The present data do not solve the problem of the pathogenesis of neomembranes any more than did the numerous earlier publications on this subject. However, they add strong support to the concept of a repetitive process within the neomembranes. The frequency of haemorrhages in neomembranes was related to their size and thickness. Most of these haemorrhages appeared to be of recent date, often definitely more recent than the neomembranes in which they were found, as indicated by the coexistence of haemorrhages without cytolysis and of foci of haemosiderin-laden haemophages within the same membrane. The frequent combination of various types of membranous lesions in a given case also indicated a repetitive pathogenetic process. Hence, we consider the neomembranes of types I and II active lesions capable of repeated haemorrhage and progression upon slight trauma, the fibrotic lesions of type IV as old and inactive.

\section{REFERENCES}

Andres, K H (1966) Die Feinstruktur des subduralen Neurothels der Katze (Felis catus L.). Naturwissenschaften, 53, 204-205.

Andres, K. H. (1967a). Zur Feinstruktur der Arachnoidalzotten bei Mammalia. Z. Zellforsch., 82, 92-109.

Andres, K. H. (1967b). Über die Feinstruktur der Arachnoidea und Dura mater von Mammalia. Z. Zellforsch., 79, 272-295.

Beggs, J. (1967). The membranous coverings of neural tissues: An electron microscopic study. J. Neuropath exp. Neurol., 26, 412-426.

Ciarla, E. (1913). Beitrag zum pathologisch-anatomischen und klinischen Studium der Pachymeningitis cerebralis haemorrhagica. Arch. Psychiat., 52, 439-491.

Christensen, E. (1941). Studier over kronisk subduralt haematom. Busck: Kobenhavn.

Christensen, E. (1956). Pathologie der intrakraniellen Blutungen. In Handbuch der Neurochirurgie, Vol. III, pp. 703-736. Edited by H. Olivecrona and W. Tönnis. Springer: Berlin

Cruveilhier, J. (1856). Traité d'anatomie pathologique générale. Vol. 3, p. 514. Ballière: Paris.

Gardner, W. J. (1932). Traumatic subdural hematoma, with particular reference to latent interval. Arch. Neurol. (Chic), 27, 847-858.

Gellerstedt, N. (1956). Erkrankungen der Dura mater. In Handbuch der speziellen pathogischen Anatomie und Histologie, Bd. XIII/4, pp. 11775-825. Edited by F. Henke and $O$. Lubarsch. Springer: Berlin.

Goodell, C. L., and Mealey, J., Jr. (1963). Pathogenesis of chronic subdural hematoma. Experimental studies. Arch. Neurol. (Chic.), 8, 429-437.

Hanke, H. (1939). Das subdurale Hämatom. Ergebn. Chir. Orthop., 32, 1-174.

Henschen, C. (1930). Zur Pathologie, Diagnostik und Therapie der 'blutenden Dura' (Pachymeningosis et Pachymeningitis haemorrhagica interna). Schweiz. med. Wschr., 60, 599-609.

Heschl, R. (1855). Compendium der allgemeinen und speziellen Anatomie. Braümuller: Wien.

Hoff, H., and Tschabitscher, H. (1953). Die intracraniellen extracerebralen Blutungen. Med. Klin., 48, 1317-1322.

Huguenin, O. (1876). Acute und chronische Entzündungen des Gehirns und seiner Häute. Ziemssens Handbuch der speziellen Pathogischen: Leipzig.

Jores, E. (1898). Über die Beziehungen primärer subduraler Blutungen zur Pachymeningitis haemorrhagica. Verh. dtsch. path. Ges., 1, 49-63.

Jores, L., and Laurent, H. (1901). Zur Histologie und Histogenese der Pachymeningitis haemorrhagica interna. Beitr. path. Anat., 29, 486-506.

Krauland, W. (1961). Uber die Quellen des akuten und chronischen subduralen Hämatoms. Thieme: Stuttgart.

Kremiansky, J. (1868). Über die Pachymeningitis interna haemorrhagica bei Menschen und Hunden. Arch. Path. Anat., 42, 129-161 and 321-351.

Krempien, B. (1967). Alternsgang der Gefässbeziehungen zwischen Dura mater cerebri und Schädeldach. Beziehungen zum Krankheitsbild der Pachymeningosis haemorrhagica interna (P.h.i). Virchows Arch. path. Anat., 342, 282-294.

Krempien, B. (1968). Über die Blutungsquelle der Durahämatome. Ein Beitrag zur Pachymeningeosis haemorrhagica interna. Virchows Arch. path. Anat., 343, 210-229. 
Leary, T. (1934). Subdural hemorrhages. J. Amer. med. Ass., 103, 897-903.

Link, K. H. (1945). Traumatische sub- und intradurale Blutung; Pachymeningitis haemorrhagica. Fischer: Jena.

Link, K., and Schleussing, H. (1955). Die offenen Verletzungen der Dura mater cerebralis und spinalis sowie der Blutleiter. Die traumatischen Blutungen im Bereich der harten Hirnhaut. In Handbuch der speziellen pathogischen Anatomie und Histologie, Vol. XIII/3, pp. 1-21. Edited by F. Henke and $O$. Lubarsch. Springer: Berlin.

Mittenzweig (1889). Subdurale Blutung aus abnorm verlaufenden Gehirnvenen. Neurol. Cbl., 8, 193-196.

Munro, D., and Merritt, H. H. (1936). Surgical pathology of subdural hematoma based on a study of hundred and five cases. Arch. Neurol. Psychiat. (Chic.), 35, 64-78.

Munro, D. (1942). Cerebral subdural hematomas. A study of three hundred and ten verified cases. New Engl. J. Med., 227, 87-95.

Pampari, D. (1938). L'ematoma sottodurale traumatico (ricerche sperimentali). Ann. ital. Chir., 17, 741-774.

Peters, G. (1951a). Die Pachymeningitis haemorrhagica interna, das intradurale Hämatom und das chronische subdurale Hamatom. Eine klinische, pathologische, pathogenetische, differentialdiagnostische und versicherungsmedizinische Betrachtung. Fortschr. Neurol. Psychiat., 19, 485-582.

Peters, G. (1951b). Spezielle Pathologie der Krankheiten des zentralen und peripheren Nervensystems. Thieme: Stuttgart.

Putnam, T. J., and Cushing, H. (1925). Chronic subdural hematoma. Arch. Surg., 11, 327-393.

Putnam, T. J., and Putnam, I. K. (1927). The experimental study of pachymeningitis haemorrhagica. J. nerv. ment. Dis., 65, 260-272.
Soos, J., and Detrehazy, K. (1955). Beiträge zur Frage der Pachymeningitis hämorrhagica intraduralis. Z. allg. Path. Anat., 93, 53-58.

Trotter, W. (1914). Chronic subdural haemorrhage of traumatic origin, and its relation to pachymeningitis haemorrhagica interna. Brit. J. Surg., 2, 271-291.

Virchow, R. (1857). Das Hämatom der Dura mater. Verh. phys.-med. Ges. Würzb., 7, 134-142.

v. Albertini, A. (1941). Zur Frage der traumatischen Genese der Pachymeningitis haemorrhagica interna. Schweiz. $Z$. Path., 4, 442-454.

v. Albertini, A. (1942). Weitere Beiträge zur Pathogenese der idiopathischen Pachymeningitis hämorrhagica interna. Schweitz Z. Path., 5, 293-309.

Wepler, W. (1951). Zur Frage der sog. Pachymeningitis hemorrhagica interna. Verh. dtsch. path. Ges., 34, 213-220.

Wepler, W. (1954a). Über das Hämatom der harten Hirnhaut. Ber. phys. med. Ges. Würzb., 66, 181-189.

Wepler, W. (1954b). Zur Pathogenese und Begutachtung des chronischen Hämatoms der Dura mater. Zbl. allg. Path., c 91, 406-412.

Wepler, W. (1959). Chronische Folgen traumatischer Schädigungen an der Dura mater cerebri. Verh. dtsch. path. Ges., 43, 90-103.

Wigglesworth, J. (1892). Remarks on the pathology of socalled pachymeningitis haemorrhagica interna. Brain, 15, 431-436.

Wolf, G. (1962). Das subdurale Hämatom und die Pachymeningitis haemorrhagica interna. Springer: Berlin.

Wolff, W. (1921). Beitrage zur Pathologie der Pachymenin gitis haemorrhagica interna. Virchows Arch., 230, 215-22 $\frac{}{6}$

Zehnder, M. (1938). Die subduralen Hämatome. Z Neurochir., 2, 339-353. 